\title{
Identification of Methylxanthines and Phenolic Compounds by UPLC-DAD-ESI-MS OTOF and Antioxidant Capacities of Beans and Dark Chocolate Bars from Three TrinitarioxForastero Cocoa (Theobroma cacao L.) Hybrids
}

\author{
Simon Perrez Akoa ${ }^{1}$, Jules Christian Djoko Kouam ${ }^{3}$, Martine Louise Ondobo ${ }^{2}$, Jude Manga Ndjaga ${ }^{3}$, Pierre \\ François Djocgoue ${ }^{3} \&$ Pierre Effa Onomo ${ }^{1 *}$ \\ ${ }^{1}$ Department of Biochemistry, Faculty of Science, University of Yaounde I, P.O. Box 812, Yaounde, Cameroon \\ ${ }^{2}$ Department of Biological Science, Higher Teacher Training College, University of Yaounde I, P.O. Box 47, \\ Yaounde, Cameroon \\ ${ }^{3}$ Department of Plant Biology, Faculty of Science, University of Yaounde I, P.O. Box 812, Yaounde, Cameroon \\ Correspondence: Pierre Effa Onomo, Department of Biochemistry, Faculty of Science, University of Yaounde I, \\ P.O. Box 812, Yaounde, Cameroon. E-mail: peffafr@yahoo.fr
}

Received: January 31, 2021

Accepted: March 2, $2021 \quad$ Online Published: March 10, 2021

doi:10.5539/jfr.v10n2p32

URL: https://doi.org/10.5539/jfr.v10n2p32

\begin{abstract}
Interest on Trinitario cocoa has continuously increased due to the fact that some genotypes of this group had inherited some characters of vigorosity from Forastero and the flavor grade of Criollo. The pronounced incompatibility between Trinitario clones orientates research on the crossing of Trinitario clones with other varieties of cocoa in order to increase productivity and cocoa beans quality. Polyphenols and methylxanthines are bioactive compounds responsible for the health benefits of cocoa and cocoa based products. Cocoa is a crop with a high content of bioactive compounds in the plant kingdom. This study aims at correlating genotypes, methylxanthines and polyphenols as well as antioxidant activity of beans and dark chocolate derived from TrinitarioxForastero hybrids. Total polyphenol content and total condensed tannin contents were determined by spectrophotometric methods. Individual bioactive compounds were identified by UPLC-DAD-ESI(+)-MS both in beans and dark chocolate bar. Results showed differences within beans of dark chocolate and between beans and dark chocolate. Beans from the hybrid $($ ( $)$ SNK10 $\times\left({ }^{1}\right)$ IMC67 recorded the highest polyphenol content $(49.18 \pm 1.55 \mathrm{mg}$ CatE/g) considering the two matrices. The highest concentration of condensed tannins $(22.81 \pm 0.69 \mathrm{mgCatE} / \mathrm{g})$ was recorded in beans obtained from the hybrid $($ ( $)$ ICS40 $\times\left({ }^{\lambda}\right)$ UPA134. Dark chocolate bar from beans of the hybrid ( $(+) \mathrm{ICS} 40 \times\left({ }^{\top}\right)$ UPA134 was the richest in condensed tannins $(18.25 \pm 0.71 \mathrm{mg}$ $\mathrm{CatE} / \mathrm{g}$ ). The total polyphenol and total condensed tannin contents, the chemical composition as well as the antioxidant activity could be genotype-dependent and were affected negatively during roasting. In fact, roasting decreased the polyphenol content and consequently the antioxidant activity. (-)-epicatechin, theobromine, ferulic and chlorogenic acids and their derivatives, procyanidin $\mathrm{C} 1$, caffeine and salicylic acid 3-O-glucose/galactose were identified in beans and/or dark chocolate.
\end{abstract}

Keywords: beans, cocoa hybrids, dark chocolate, health benefits, secondary metabolites, UPLC-DAD-ESI(+)-MS

\section{Introduction}

During the last decades, cocoa and cocoa based products especially chocolate, have incontestably become one of the most attractive foods worldwide. This unprecedented enthusiasm for cocoa and cocoa based products is due to several research findings which mentioned the positive impacts of cocoa and chocolate in the prevention of many diseases. The biochemical composition of cocoa and chocolate provides vital information not only for improving the consumer's health but also for the improvement of cocoa/chocolate quality.

Chocolate is the generic name for the homogenous products obtained from cocoa and cocoa materials with sugars, milk products, flavoring substances and other food ingredients (Codex Standard. 87. 1981, Rev.1:2003). It is considered a luxury food and one of the most valued flavors worldwide (Liu et al., 2015). Chocolate is 
consumed frequently for its pleasant, stimulant, and euphorizing effects (Torres-Moreno et al., 2012). The primary chocolate categories are dark, milk and white chocolate (Afoakwa et al., 2007). The widely enjoyed chocolate-flavor makes it a favorite ingredient in bakery, ice cream, beverage, syrup production and as confection in itself (Lecumbersi et al., 2007).

Polyphenols and methylxanthines are two main active metabolites in cocoa and chocolate. Polyphenols represent about 10 to $18 \%$ of unfermented dry cocoa beans weight (Gómez-Juaristi et al., 2019; Martínez-López et al., 2014a; Niemenak et al., 2006; Wollsgast \& Anklam, 2000). Stored in so-called cotyledons, polyphenols confer astringent and bitter sensations and contribute significantly to the green and fruity flavors of cocoa liquors (Noor-Soffalina et al., 2009). Also, polyphenols are responsible for the positive health benefits associated with the consumption of cocoa and cocoa based products. Three main groups of polyphenols have been identified in cocoa/chocolate. They include catechins (flavan-3-ols, $\sim 37 \%$ ), anthocyanins $(\sim 4 \%)$, and proanthocyanidins $(\sim 58 \%)$. Monomers account for $5-10 \%$ of the total cocoa polyphenols and polymers account for approximately $90 \%$ of the total cocoa polyphenols (Khan \& Nicod, 2012). According to some studies, (-)-epicatechin appears to be the most abundant catechin representing about 35\% of the total phenolic content (González-Barrio et al., 2020; Oracz et al., 2015). Besides the different health effects, studies underscored the role of polyphenols in modulating eicosanoid synthesis as well as increasing nitric oxide synthesis which in turn inhibits the oxidation of low density lipoprotein (LDL). This inhibits platelet activation thereby stimulating the production of anti-inflammatory cytokines and inhibiting pro-inflammatory cytokine production (Rimbach et al., 2009; Niemenak et al., 2006). Although most of the studies attribute the health benefits of cocoa or cocoa based products to polyphenols, it should be noted that cocoa and its products are not only rich in polyphenols, but also contain methylxanthines that account for about 3.2\% of defatted unsweetened chocolate composition (Camillo \& Benitez, 2000). These purine alkaloids are present in a variety of pharmaceutical products and drugs since they are known to stimulate the central nervous system, induce gastric secretions, and act as diuretics (Gómez-Juaristi et al. (2019); Camillo \& Benitez, 2000; Evans \& Griffiths, 1999). Theobromine was found as the major alkaloid in Theobroma cacao. Cocoa seeds contain between 1 and $4 \%$ weight of this compound. It is therefore a plant with tremendous economic importance because of its use in beverages and chocolates (Ashihara \& Suzuki, 2004; Caudle et al., 2001).

Cocoa (Theobroma cacao L.) is a perennial crop widely cultivated in Africa, America and Asia and whose beans are used to produce cocoa powder and chocolate (Cuatrecasas, 1964). According to the international cocoa committee (ICCO, 2019), over 4.7 million tons of cocoa were produced during the 2018/2019 crop year. World leaders in cocoa beans production include Ivory Coast, Ghana, Indonesia, Cameroon, Ecuador, Nigeria and Brazil. In the last decade, the African continent accounted for about $3 / 4$ of the total annual cocoa production (ICCO, 2019; Patras et al., 2014). Three major groups of cocoa are known: Criollo, Forastero and Trinitario. Criollo cocoa is known for its fine aroma. Forastero, in its majority is classified as bulk cocoa. Trinitario cocoa is a hybrid of Forastero and Criollo groups. Research on this cocoa group highlighted that some of them can be classified as fine/flavor cocoa. Meantime, the problem of incompatibility between Trinitario clones limits production of pure Trinitario cocoa (Loor Solórzano, 2007). Crossing between other groups of cocoa may increase the production of Trinitario cocoa thereby ensuring cocoa quality. In Cameroon, Trinitario cocoa is represented by SNK and ICS clones (Efombagn et al., 2008). It is well known that the quality of cocoa and cocoa based products depends on the genotype and post-harvest practices as well as technological processes. This quality is a function of both chemical composition and concentration of cocoa beans and chocolate. Kongor et al. (2016) mentioned that genotypes of cocoa beans are significantly related to the chemical composition. Methylxanthine and polyphenol content in cocoa is highly dependent on the cocoa genotype (Urbanska et al., 2019; Hernández-Hernández et al., 2018; Aprotosoaie et al., 2016). Diversity of polyphenol and methylxanthine composition have been reported in cocoa beans within the same clone/variety (Noor-Ariefandie \& Fan Zhu, 2019). In fact, the total phenol content and specifically the type of polyphenol is associated with antioxidant capacity. Presently, no study correlates the total polyphenol content, the chemical composition as well as the antioxidant activity of dried fermented cocoa beans and their corresponding dark chocolate from specific TrinitarioxForastero hybrids.

This study seeks to assess variations in polyphenol content, antioxidant activity as well as identification of polyphenols and purine alkaloids in fermented dry cocoa beans from three TinitarioxForastero hybrids and their corresponding dark chocolate bars. 


\section{Materials and Methods}

\subsection{Materials}

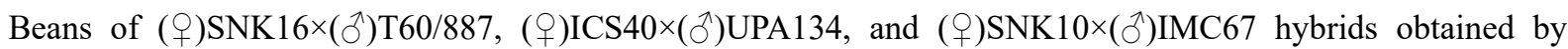
hand-pollination during two consecutive crop years (2017 and 2018) were fermented for $144 \mathrm{~h}$ periodically spread after every $48 \mathrm{~h}$. After ten days' sun-drying, the cocoa beans were sent to the laboratory of Food Technology of the Institute of Agricultural Research for Development (IRAD), Yaounde station for chocolate production. Dark chocolates (100 g and $400 \mathrm{~g}$ chocolate bars) were produced (67\% liquor, 23\% grey cane sugar and $10 \%$ cocoa butter). Fermented and dried beans were deshelled and roasted in a vacuum oven (Heratherm, Thermo scientific) at $120^{\circ} \mathrm{C}$ for $20 \mathrm{~min}$. After roasting, cocoa liquor was obtained using a plenary mixer (Varjomatic, England) at $45^{\circ} \mathrm{C}$ (heat gun) for $4 \mathrm{~h}$. The dark chocolates were obtained by mixing cocoa butter and cane sugar for $15 \mathrm{~min}$ at $45^{\circ} \mathrm{C}$. Dark chocolate samples were molded and stored at $4^{\circ} \mathrm{C}$ for $24 \mathrm{~h}$ before being wrapped with aluminum paper. For bioactive compounds analysis, the dark wrapped chocolates were kept in refrigerator (Liebehrr, Poland) at $6^{\circ} \mathrm{C}$ before analysis

Folin-Ciocalteu phenol was purchased from Sigma-Aldrich (St. Louis, Mo, USA). $\mathrm{Na}_{2} \mathrm{CO}_{3}$ and caffein were purchased from Merk (Darmstadt, Germany). Methanol, chlorogenic acid, theobromine, quercetin, catechin, ferulic acid, caffeic acid were obtained from Sigma-Aldrich. Acetonitrile was of HPLC grade purity (Romyl, Teknokroma, Barcelona, Spain) and n-hexane was obtained from VWR international (Fontanay-sous-bois, France). All chemicals were of analytical and HPLC grades.

\subsection{Total Polyphenols and Methylxanthines Extraction}

Approximately 20 fermented dry cocoa beans were randomly selected from $1 \mathrm{~kg}$ of the sample. Prior to extraction, samples of beans and chocolate $(20 \mathrm{~g})$ were first defatted. The samples of fermented dry cocoa beans of each hybrid and its corresponding dark chocolate were manually ground to fine particle size of $0.5 \mu \mathrm{m}$ for extraction. The cocoa mass and chocolate mass samples were defatted with $n$-hexane $(1: 5 \mathrm{~m} / \mathrm{v})$ for five hours using a Soxhlet apparatus. The extraction procedure was done as described by Hernández-Hernández et al. (2018) with light modifications. Briefly, $500 \mathrm{mg}$ of defatted bean powder or dark chocolate were mixed with $5 \mathrm{ml}$ methanol: water: hydrogen chloride (80/19.5/0.5) and vortexed for 5 min. The mixture was then centrifuged at $3500 \mathrm{rpm}$ (5702 R Centrifuge, Eppendorf) at $4^{\circ} \mathrm{C}$ for $10 \mathrm{~min}$. The supernatant was kept and the filtrate was mixed with $2 \mathrm{~mL}$ of the above solution and centrifuged in the same conditions. The second supernatant was mixed with the first one and the solution obtained was used as bioactive compounds extract.

\subsection{Antioxidant Capacity}

\subsubsection{DPPH Radical Scavenging Activity}

Free-radical scavenging activity of fermented dry cocoa beans and dark chocolate extracts was measured using the method described by Scherer and Godoy (2009) with slight modifications, where the DPPH removes a hydrogen atom from the molecule under study resulting to a decrease in absorbance at $517 \mathrm{~nm}$. For analysis, 500 $\mu \mathrm{L}$ of the solution of DPPH (Sigma-Aldrich, Steinheim, Germany) at a concentration of DPPH (400 $\mu \mathrm{M})$ was added to $50 \mu \mathrm{L}$ of each chocolate or beans extract prepared at four different concentrations: 50; 100; 200 and 500 $\mu \mathrm{g} / \mathrm{mL}$ in methanol, protected from light. The samples were allowed to stand at $25^{\circ} \mathrm{C}$ for $0.5 \mathrm{~h}$ after which the absorbance was read at $517 \mathrm{~nm}$ using a spectrophotometer (UV-1605 Shimadzu spectrophotometer). All analyses were performed in triplicate. Gallic acid was used as control. The antiradical activity was expressed as a percentage of reduced polyphenols and calculated as follows:

$$
\text { Antiradical activity }(\%)=[1-(\text { Abs sample 517/Abs control 517) }] \times 100
$$

Antioxidant activity index (AAI) was calculated as follows: AAI = (final concentration of DPPH in the reaction)/ $/ \mathrm{IC}_{50}$, where the final concentration of the reaction was $143.38 \mathrm{mg} \cdot \mathrm{mL}^{-1}$. The concentration for $50 \%$ inhibition $\left(\mathrm{IC}_{50}\right)$ was calculated by the linear regression equation between the extract concentration and the corresponding scavenging effect. Scherer and Godoy (2009) established the following criteria of AAI values for plant extracts: poor activity $<0.05<$ moderate $<1.0<$ strong $<2.0<$ very strong.

\subsubsection{Ferric Reducing/Antioxidant Power (FRAP)}

The ferric reducing/antioxidant power (FRAP) assay was carried out according to a standard procedure by Benzie \& Strain (1996) with some modifications. FRAP reagent was prepared as follows: $3 \mathrm{~mL}$ of TPTZ (2,4,6-Tripyridyl-s-Triazine) solution $(10 \mathrm{mM})$ in $50 \mathrm{mM} \mathrm{HCl}$ added to $3 \mathrm{~mL}$ of $\mathrm{FeCl}_{3} .7 \mathrm{H}_{2} \mathrm{O}$ and $25 \mathrm{~mL}$ of acetate buffer $(0.25 \mathrm{mM} \mathrm{pH} 3.8)$. The solution was incubated at $37^{\circ} \mathrm{C}$ for 30 minutes. For antioxidant activity evaluation, $1000 \mu \mathrm{L}$ of the FRAP reagent was mixed with $400 \mu \mathrm{L}$ of distilled water and $100 \mu \mathrm{L}$ of samples or 
standard. Samples and standards were homogenized and incubated at $37{ }^{\circ} \mathrm{C}$ for 30 minutes, and the reading was performed at $593 \mathrm{~nm}$ on the spectrophotometer (UV-1605 Shimadzu spectrophotometer). Gallic acid solution was used as a standard. Results were expressed as gallic acid equivalent (micrograms) (GAE)/milligrams (mg) of dry fat-free matter (ffm). All analyses were performed in triplicate.

\subsection{Determination of Total Polyphenols and Total Condensed Tannins}

Total phenolic content was determined by the spectrophotometric method with Folin-Ciocalteu reagent according to (Singleton \& Rossi, 1965). Folin-Ciocalteu reagent $(1 \mathrm{~mL})$ and $20 \%(w / v)$ sodium carbonate $(25 \mu \mathrm{L})$ were added to the proper amount of sample (estimated to achieve absorbance reading in the range of 0.1-0.8). Subsequently, the mixture was vortexed using STUART vortex mixer ( 3000 x $g ; 30 \mathrm{~s}$; Biocote, UK) and then the samples were left in a dark place at ambient temperature for $60 \mathrm{~min}$. After that time, the absorbance was read using GENWAY 6305 spectrophotometer (Germany) at the wavelength of $760 \mathrm{~nm}$. Total phenolic content was read against calibration curve prepared for the $\mathrm{MeOH} / \mathrm{H}_{2} \mathrm{O} / \mathrm{HCl}(80 / 19.5 / 0.5)$ solution of chlorogenic acid.

Proanthocyanidins (condensed tannins) were analyzed by the procedure described by Hagermann (2002) with some modifications. Briefly, ButOH/HCl assay was carried out by mixing $0,5 \mathrm{~mL}$ of dark chocolate or beans extract with $3 \mathrm{~mL}$ of a solution of n-ButOH-conc. $\mathrm{HCl}(95: 5, \mathrm{v} / \mathrm{v})$ and $0.1 \mathrm{~mL}$ of a $2 \mathrm{~g} / 100 \mathrm{~g}$ solution of $\mathrm{NH}_{4} \mathrm{Fe}\left(\mathrm{SO}_{4}\right)_{2}$ in $2 \mathrm{~mol} / \mathrm{L} \mathrm{HCl}$. The solution was capped and thoroughly mixed and heated for $45 \mathrm{~min}$ at $95^{\circ} \mathrm{C}$ in a water bath. The sample was cooled and the visible spectrum recorded at $\lambda=550 \mathrm{~nm}$. The blank value of the ButOH-HCl-FeIII solvent was subtracted. All measurements were performed in triplicate. The quantity of condensed tannins was determined from a standard curve of catechin treated with ButOH-HCl-FeIII mixture, and expressed as mg catechin equivalents (CatE)/g of sample.

\subsection{UPLC-DAD-ESI(+)-MS of Individual Phenolic and Methylxanthine Compounds}

All the bioactive compound extracts were prepared in a concentration of $50 \mathrm{mg} / \mathrm{mL}$ then filtered through a syringe-filter-membrane. Aliquots of $5.00 \mu \mathrm{L}$ were injected into the UPLC-DAD-MS Dionex Ultimate 3000 HPLC (Germany) were used to perform the analyses. High Resolution Electro Spray Ionization - Mass Spectra (HRESI-MS) were obtained with an OTOF Spectrometer (Bruker, Germany) equipped with a HRESI source and a UV-visible absorbance detector. The spectrometer was operated in positive mode (m/z range: $100-1200$, with a scan rate of $2.5 \mathrm{~Hz}$ ) with automatic gain control to provide high-accuracy mass measurements within $2 \mathrm{ppm}$ deviation using $\mathrm{Na}$ Formate as calibrant. Mass spectra were simultaneously acquired using electrospray ionization in the positive ionization mode. The following parameters were used for experiments: spray voltage of $4.5 \mathrm{kV}$, capillary temperature of $200^{\circ} \mathrm{C}$. Nitrogen was used as sheath gas $(10 \mathrm{~L} / \mathrm{min})$. The spectrometer was attached to an Ultimate 3000 (Thermo Fisher, USA) HPLC system consisting of LC-pump, UV traces were measured between $200-600 \mathrm{~nm}$, auto sampler (injection volume $5 \mu \mathrm{L}$ ) and column oven $\left(30.0^{\circ} \mathrm{C}\right)$. The separations were performed using a Poroshell 120A RP-C18 $\left(50 \times 3.0 \mathrm{~mm}, 2.7 \mu \mathrm{m}\right.$ particle size) with $\mathrm{H}_{2} \mathrm{O}(+0.1 \%$ $\mathrm{HCOOH}, \mathrm{A} /$ acetonitrile $(+0.1 \% \mathrm{HCOOH}, \mathrm{B})$ gradient (flow rate $200 \mu \mathrm{L} / \mathrm{min})$. Samples were analyzed using a gradient program as follows: $5 \% \mathrm{~B}$ isocratic for $0.5 \mathrm{~min}$, followed by a linear gradient up to $95 \% \mathrm{~B}$ for $4.5 \mathrm{~min}$, after that an isocratic system containing $5 \% \mathrm{~B}$ was spent for $4 \mathrm{~min}$. the system returned to its initial condition (95\% A) within $1 \mathrm{~min}$, and was equilibrated for $1 \mathrm{~min}$. Eight standard compounds were used for identification of bioactive compounds using LC-MS apparatus. The eight standard molecules were (+)-catechin, (-)-epicatechin, theobromine, caffeine, quercetin, caffeic acid, chlorogenic and ferulic acids.

\subsection{Statistical Analysis}

Results were obtained by performing analysis of variance (ANOVA) followed by Tukey HSD at $\mathrm{P}<5 \%$ to compare means with the assistance of SPSS 25.0 for windows. Gaphpad 5.0 software was used to perform the scavenging activity of extracts at different concentrations. Cluster analysis with antioxidant activity index (AAI) of cocoa beans and chocolate, using the unweighted pairwise group methods with arithmetical average (UPGMA) on the basis of Nei's (1978) genetic distance were performed with the assistance of SPAD 5.5.

\section{Results and Discussion}

\subsection{Total Polyphenol and Total Condensed Tannin Contents}

The highest concentration of polyphenols was obtained for hybrid (P)SNK10×(ð)IMC67 (Table 1). Inversely, dark chocolates from the hybrid $($ ( $)$ ICS40 $\times\left(0^{\lambda}\right)$ UPA134 showed the highest concentration of polyphenol and condensed tannins. In addition, the highest condensed tannins content was obtained in ( $(+) \operatorname{ICS} 40 \times\left({ }^{\lambda}\right) \mathrm{UPA} 134$ dried fermented beans.

The presence of polyphenols and their main subclasses in cocoa estimated by spectrophotometric methods showed many differences among hybrids and matrixes. Some hybrids in the same conditions of postharvest 
practices and technological processes are richer in bioactive compounds than others. It is well known that the bioactive compound content of cocoa beans depends on many factors amongst which the genotype/variety of cocoa. Several authors highlighted that different cocoa genotypes/varieties have different contents of polyphenols in the same conditions (Noor Ariefandie et Fan Zhu, 2019; Oracz et al., 2015; Niemenak et al., 2006). In a general point of view, the content of polyphenols seemed to be in accordance with data in literature. Many studies have already presented the concentration of polyphenols in cocoa. It has been demonstrated that the amount of polyphenols represents 5\% in fermented dry beans of Forastero cocoa type (Albertini et al., 2015). Our results recorded approximatively the same quantity in fermented dry beans of $(+)$ ICS40×(ð)UPA234 hybrid. It has been shown that polyphenol content is higher in Forastero cocoa than in Trinitario and Criollo groups (Tomas-Barberan, 2012). On the contrary, the proanthocyanidins content was higher in Criollo classified as fine/flavour cocoa than in Trintario and Forastero cocoas (Giacometti et al., 2015). The content of proanthocyanidin in cocoa was recognized for discriminating cocoa varieties. Results of procyanidin concentrations in different hybrids showed that both beans and bar from the hybrid ( + )ICS40 $\times\left({ }^{1}\right)$ UPA134 could be discriminated by others. Many health benefits of polyphenols from cocoa are well described. In a meta-analysis of eight short-term trials, consumption of cocoa was found to reduce the LDL cholesterol content (Jia et al., 2010). In addition, an epidemiological study revealed a consistent increase in blood flow velocity from $8 \%$ after 1 week of cocoa consumption to $10 \%$ following 2 -week consumption of flavanol-rich cocoa (Sorond, 2008). The antioxidant activity of cocoa was mainly attributed to this group of bioactive compounds. The processing of beans led to a reduction in bioactive compound content from fermented dry beans to chocolates. This observation agrees with the data in literature. Certain authors highlighted that Polyphenols are thermolabile molecules whose content reduces in high temperatures and prolonged roasting (Urbanska et Kowalska, 2019; Kothe et al., 2013; Ramli et al., 2006). On the other hand, it was considered that the roasting at low temperatures for a short time better preserves polyphenol content (Ioannone et al., 2015). Temperatures ranging from $120^{\circ}-140^{\circ} \mathrm{C}$ for 5 to $35 \mathrm{~min}$ were recommended. From our results, it appears that there is not a fix percentage of reduction of polyphenol content from beans to bar. Also, beans with high polyphenol content produce chocolate with similar polyphenol content as well.

Table 1. Concentrations $(\mathrm{mg} / \mathrm{g} \mathrm{ffm})$ of individual bioactive compounds in fermented dry beans and dark chocolates

\begin{tabular}{|c|c|c|c|}
\hline Samples & Matrices & Total polyphenols & Total Condensed tannins \\
\hline \multirow{3}{*}{ (q)SNK16×(ठ)T60/887 } & Beans & $44.03 \pm 1.11^{\mathrm{c}}$ & $21.73 \pm 0.51^{b}$ \\
\hline & Bar & $38.07 \pm 2.21^{\mathrm{a}}$ & $16.25 \pm 0.79^{\mathrm{a}}$ \\
\hline & Beans & $43.37 \pm 1.39^{\mathrm{c}}$ & $22.81 \pm 0.69^{\mathrm{b}}$ \\
\hline \multirow[t]{2}{*}{ (†)ICS40×(ð)UPA134 } & Bar & $41.84 \pm 1.07^{\mathrm{bc}}$ & $18.25 \pm 0.71^{\mathrm{ab}}$ \\
\hline & Beans & $49.18 \pm 1.55^{\mathrm{d}}$ & $19.36 \pm 0.12^{\mathrm{ab}}$ \\
\hline (ㅇ)SNK10×(ふ) IMC67 & Bar & $40.28 \pm 0.27^{\mathrm{b}}$ & $17.33 \pm 0.18^{\mathrm{a}}$ \\
\hline
\end{tabular}

Values in the same column with different letters were significantly different $(\mathrm{p}<0.05)$

\subsection{Identification of Phenolic and Methylxanthine Individual Compounds by UPLC-DAD-ESI(+)/MS OTOF}

Among the eight standard molecules, except (+)-catechin, caffeic acid and quercetin, five of them were detected in cocoa beans or dark chocolate. We noted the presence of methylxanthines (theobromine and caffeine) with high peaks.

Data of Many individual (+)HRESI-MS spectra served for confirmation of individual compounds. The identification was performed by the specific adducts of a given molecule. (-)-epicatechin was identified by its adducts $[\mathrm{M}+\mathrm{H}]^{+}=291.1133,[\mathrm{M}+\mathrm{Na}]^{+}=313.1036$ and $[\mathrm{M}+\mathrm{K}]^{+}=329.1207$. The maximum absorption at $278 \mathrm{~nm}$ and the retention time of 2.8 min confirmed the presence of this molecule (Fig. 1). Several studies had mentioned the presence of (-)-epicatechin in cocoa and cocoa based products. (-)-epicatechin was found to be the second major individual compound in cocoa (Hernández-Hernández et al., 2018; Noor-Ariefandie \& Fan Zhu, 2019). There was a difference between beans and bar intensities of The (-)-epicatechin UV and (+)HRESI-MS (Fig. 1) spectra. These peaks were higher in beans than bars and the intensity was genotype-dependent (Fig. 1A and 1B). Results obtained by Mikołajczak \& Tanska (2019) and Peláez et al. (2016) highlighted that there is a significant difference between (-)-epicatechin content in beans or chocolate. 


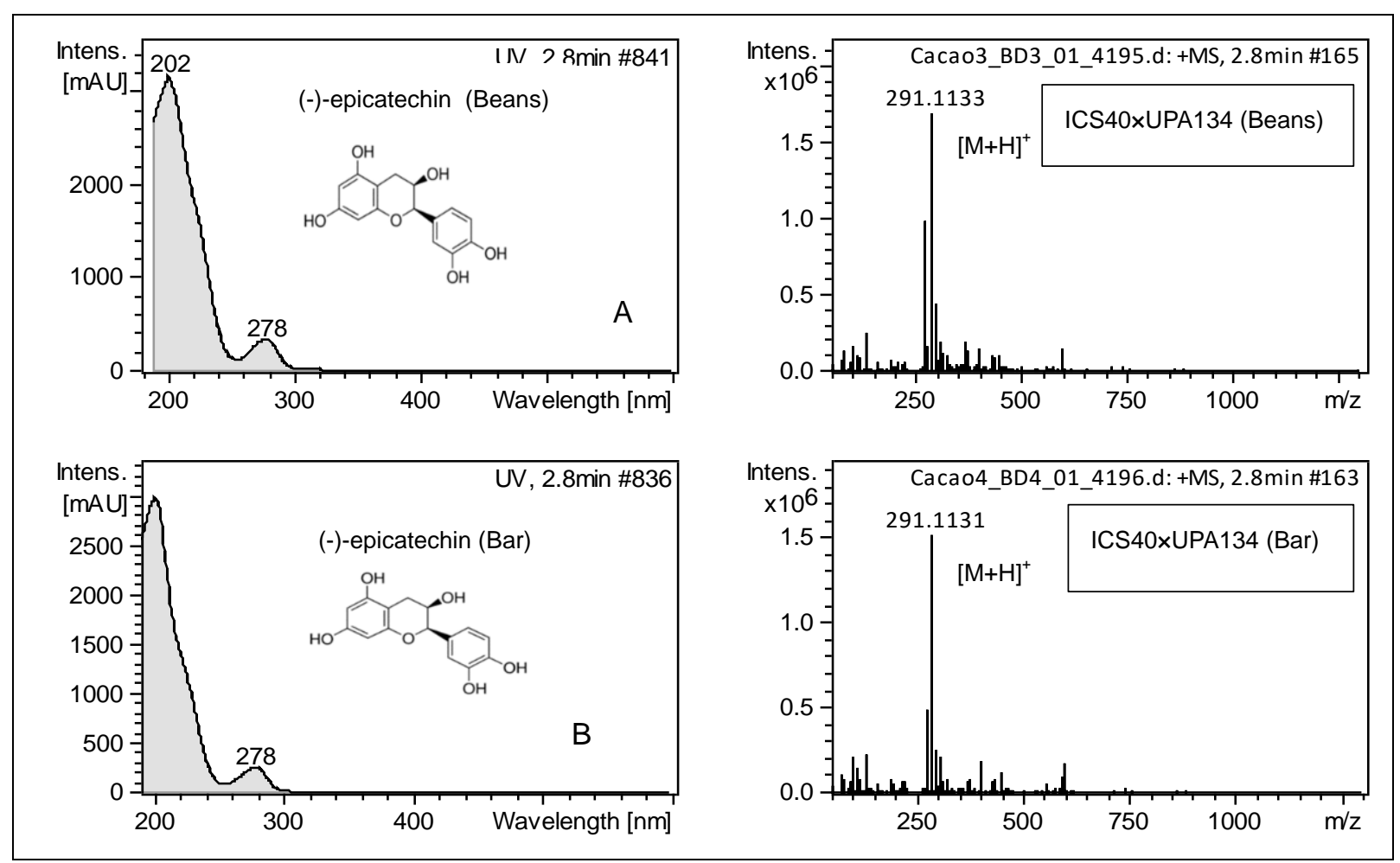

Figure 1. UV and (+)HRESI-MS spectra of (-)-epicatechin in beans (A) and dark chocolate bar (B) from ICS40×UPA134 hybrid identified by UPLC-DAD-ESI(+)/MS OTOF

The different adducts of theobromine were identified as follows: $[\mathrm{M}+\mathrm{H}]^{+}=181.0998,[2 \mathrm{M}+\mathrm{Na}]^{+}=383.1518$ and $[2 \mathrm{M}+\mathrm{K}]^{+}=399.1217$. This molecule had as retention time $0.8 \mathrm{~min}$ and absorbed at $274 \mathrm{~nm}$ (Fig. 2A). Caffeine also had the same wavelength $(274 \mathrm{~nm})$ of theobromine and the adduct $[\mathrm{M}+\mathrm{H}]^{+}=195.1109$ added with the retention time of $2.3 \mathrm{~min}$ confirmed the presence of this molecule (Fig. 2B). The presence of methylxanthines specifically theobromine and caffeine help to confirm these compounds in cocoa and cocoa based products. It has been noted that theobromine $\left(\mathrm{C}_{7} \mathrm{H}_{8} \mathrm{~N}_{4} \mathrm{O}_{2}, 3,7\right.$-dimethyl-xanthine) is the main methylxanthine in cocoa that represents approximatively $4 \%$ of cocoa butter, or between 0.8 and $2 \%$ of total cocoa bean dry weight (Barišic et al., 2019; Hernández-Hernández et al., 2018; Carrillo et al., 2014). Methylxanthines, mainly caffeine, enhance physical and intellectual performance, mitigate fatigue, and cause a feeling of alertness (Gómez-Juaristi et al., 2019; Martínez-López et al., 2014b; Aprotosoaie \& Stanescu, 2010). Theobromine has a weaker effect than caffeine and in the case of cocoa products, its content is even lower or different from caffeine (Franco et al., 2013). Studies have shown that theobromine appears to be even safer for humans than caffeine (Franco et al., 2013). 


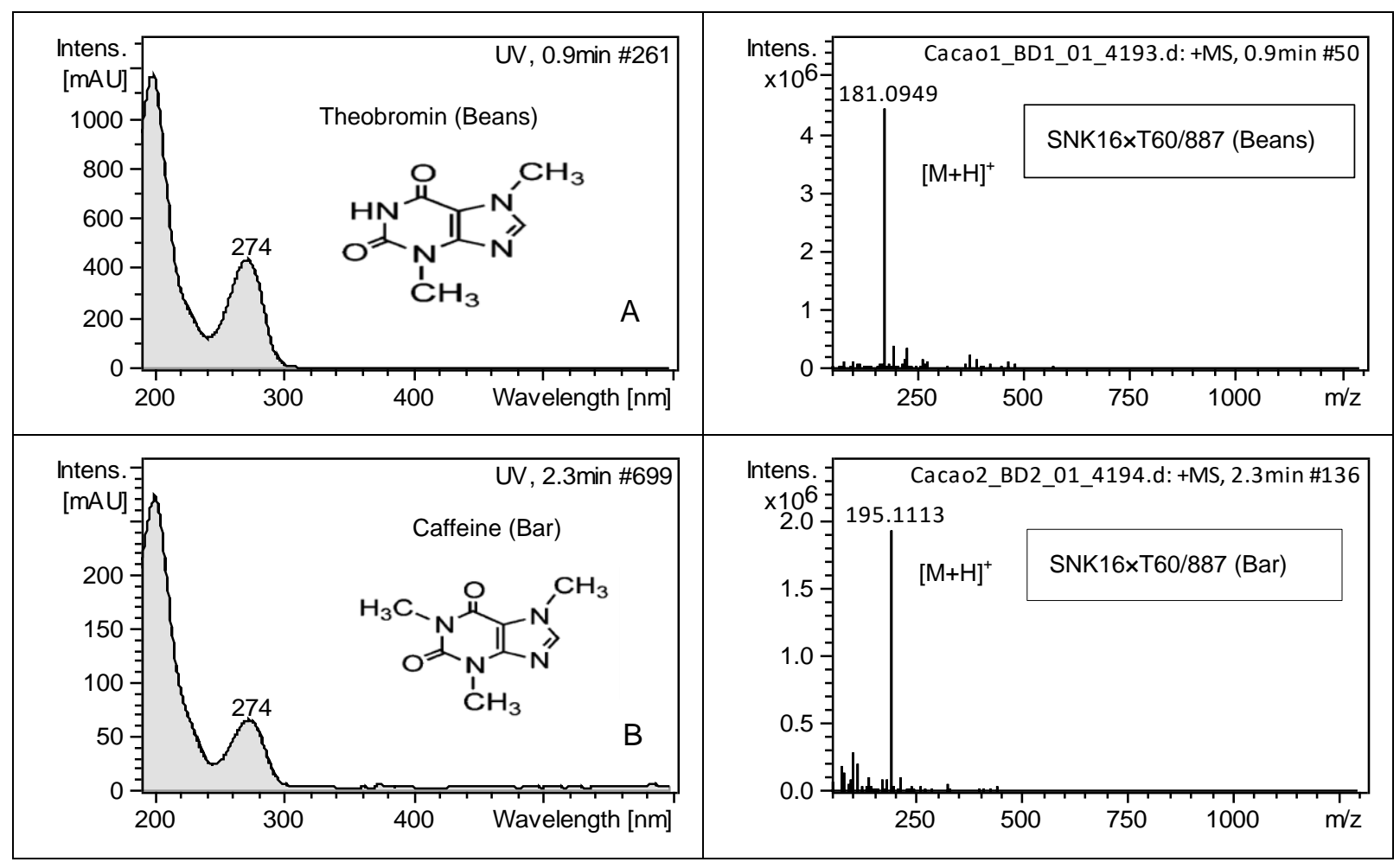

Figure 2. UV and (+)HRESI-MS spectra of theobromine (A) and caffeine (B) identified from SNK16×T60/887 hybrid by UPLC-DAD-ESI(+)/MS OTOF

The presence of ferulic acid was detected by the adducts $[\mathrm{M}+\mathrm{H}]^{+}=195.1110$ and $[2 \mathrm{M}+\mathrm{Na}]^{+}=413.3090$. The wavelength of this molecule was $222 \mathrm{~nm}$ and the retention time was obtained at $5.9 \mathrm{~min}$ (Fig. 3A). The ferulic acid, an antioxidant phenolic acid compound was identified in three endemic Nolana species by HPLC-PDA-ESI(-)-MS (Simirgiotis et al., 2015). The maximum wavelengths of ferulic acid were 246 and 310 $\mathrm{nm}$ respectively. The presence of ferulic acid in these cocoa beans and their dark chocolate was an important indicator for consumer's health. It had been shown that ferulic acid can inhibit ultraviolet C-induced oxidative DNA damage, being as effective as glutathione, $\alpha$ - tocopherol, and vitamin C. In humans, flavanol-rich cocoa products increase the total plasma antioxidant capacity (Sarriá et al., 2020; Keen et al., 2005). The chlorogenic acid also had $222(325) \mathrm{nm}$ as wavelength and $6.5 \mathrm{~min}$ as retention time. Its two adducts are $[\mathrm{M}+\mathrm{H}]^{+}=355.3124$ and $[\mathrm{M}+\mathrm{K}]^{+}=393.3296$. Faisal et al. (2013) identified chlorogenic acid in cocoa using HPLC-DAD-ESI-MS/MS optimized method. The authors obtained two maximum wavelengths in negative mode ESI for this compound 226 and $300 \mathrm{~nm}$ respectively. The acidity and antioxidant activity of chlorogenic acid were reported and this phenolic compound was richer in coffee than in cocoa (Rao \& Fuller, 2018) 


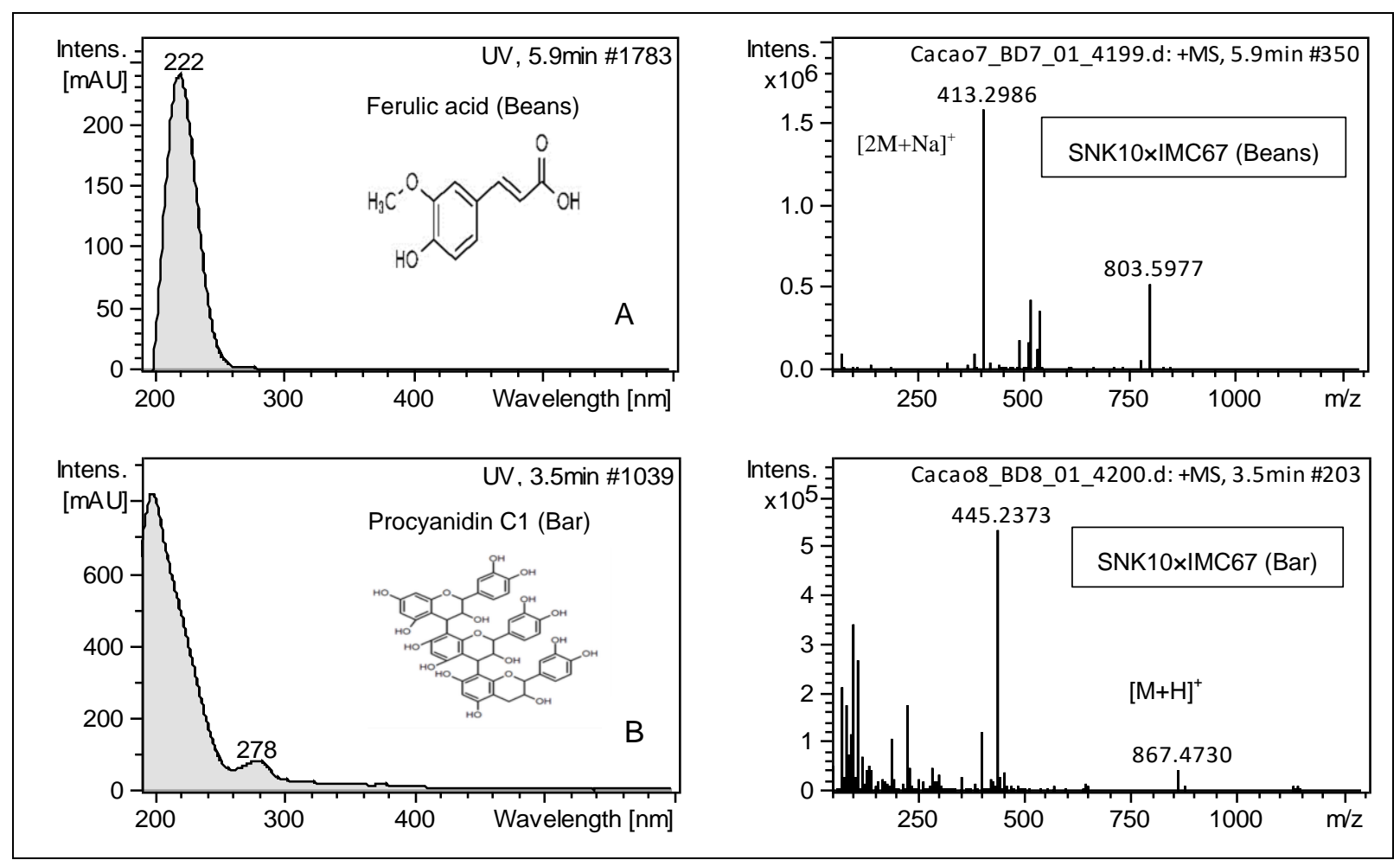

Figure 3. UV and (+)HRESI-MS spectra of chlorogenic acid (A) and ferulic acid (B) identified from SNK10×IMC67 by UPLC-DAD-ESI(+)/MS OTOF

With the assistance of the retention time (RT), the ultra-violet (UV) and (+)HRESI-MS, other compounds were recorded. The adducts of $[\mathrm{M}+\mathrm{H}]^{+}=867.4730$ and fragments $\mathrm{m} / \mathrm{z}=289.1176, \mathrm{~m} / \mathrm{z}=445.23$ and $\mathrm{m} / \mathrm{z}=577.1748$ were specific to procyanidin $\mathrm{C} 1$. The molecule wavelength was $278 \mathrm{~nm}$ (Table 2). This compound was described in cocoa and cocoa based product so far (González-Barrio et al., 2020; Noor-Ariefandie \& Fan Zhu, 2019; Guehi-François, 2019; Patras et al., 2014). Procyanidin C1 was observed in the two hybrids of SNK:

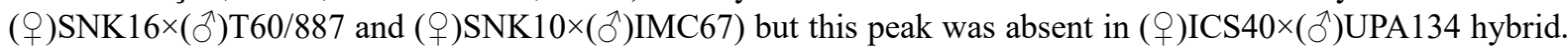
Salicylic acid-3-O-glucosidetgalactoside and isorhamnetin-3-O-glucoside were identified using the same procedure. Like procyanidin $\mathrm{C} 1$, these two polyphenols were also reported in cocoa.

Three peaks were recorded at 4.8, 5 and 5.1 min respectively in beans of the three hybrids considered. All these peaks had the wavelength of $218 \mathrm{~nm}$. On the contrary, in dark chocolates, only one peak appeared at $5 \mathrm{~min}$. The wavelength and the retention time of each peak and the different $\mathrm{m} / \mathrm{z}$ ratios obtained were given in Table 2 . With respect to total polyphenol and condensed tannins contents, we observed a reduction in peak intensities from beans to bars. The chronological appearance of different individual polyphenol and methylxanthine compound permits their classification into groups. We obtained first flavan-3-ols (epicatechin) and methylxanthine. The second group was composed of phenolic acids (chlorogenic, ferulic and salicylic acids). A similar order was obtained with these individual compounds (Faisil et al., 2013). 
Table 2. Tentative identification of phenolic compounds in cocoa beans and dark chocolate bar using UPLC-DAD-ESI(+)-MS OTOF

\begin{tabular}{|c|c|c|c|c|c|c|c|}
\hline Proposed molecule name & Ionic species & $\mathrm{m} / \mathrm{z}$ & $\begin{array}{c}\text { Calculated } \\
\text { mass }\end{array}$ & $\begin{array}{c}\text { Detected } \\
\text { mass }\end{array}$ & $\begin{array}{l}\text { Acuracy } \\
\text { (Da) }\end{array}$ & $\begin{array}{l}\mathrm{UV} \\
(\mathrm{nm})\end{array}$ & $\begin{array}{l}\text { RT } \\
(\mathrm{min})\end{array}$ \\
\hline Theobromine & $\begin{array}{l}{[\mathrm{M}+\mathrm{H}]+,} \\
{[2 \mathrm{M}+\mathrm{Na}]+,[2 \mathrm{M}+\mathrm{K}]+}\end{array}$ & $\begin{array}{l}\text { 181.0998; 383.1518; } \\
399.1217\end{array}$ & 180.1640 & 180.0918 & -0.0692 & 274 & 0.8 \\
\hline Caffein & {$[\mathrm{M}+\mathrm{H}]+,[\mathrm{M}+\mathrm{Na}]+$} & $195.1109 ; 217.0978$ & 194.1900 & 194.1029 & -0.0870 & 274 & 2.3 \\
\hline Epicatechin & $\begin{array}{l}{[\mathrm{M}+\mathrm{H}]+,[\mathrm{M}+\mathrm{Na}]+,} \\
{[\mathrm{M}+\mathrm{K}]+}\end{array}$ & $\begin{array}{l}291.1133 ; 313.1036 ; \\
329.1207\end{array}$ & 290.2710 & 290.1053 & -0.1657 & 278 & 2.8 \\
\hline Procyanidin $\mathrm{C} 1$ & $\mathrm{M}+\mathrm{H}]+$ & 867.4730 & 866.8000 & 866.4650 & -0.335 & 278 & 3.4 \\
\hline $\begin{array}{l}\text { Isorhamnetin-3-0-Glucoside } \\
\text { /galactoside }\end{array}$ & $\begin{array}{l}{[\mathrm{M}]+,[\mathrm{M}+\mathrm{Na}]+,} \\
{[2 \mathrm{M}+\mathrm{H}]+}\end{array}$ & $\begin{array}{l}478,3291 ; 500.3133 ; \\
955.6409\end{array}$ & 478.4030 & 478.3291 & -0.0739 & $\begin{array}{l}218 \\
367\end{array}$ & 4.8 \\
\hline Salicylic acid & {$[\mathrm{M}+\mathrm{H}]+,[\mathrm{M}+\mathrm{Na}]+$} & $301.1684 ; 339.2799$ & 300.2600 & 300.1604 & -0.0996 & 218 & 5 \\
\hline Salicylic acid derivatives & {$[\mathrm{M}+\mathrm{H}]+,[\mathrm{M}+\mathrm{Na}]+$} & $301.1684 ; 339.2799$ & 300.2600 & 300.1604 & -0.0996 & 218 & 5.1 \\
\hline Ferulic acid & {$[\mathrm{M}+\mathrm{H}]+,[\mathrm{M}+\mathrm{Na}]+$} & $195.1110 ; 413.3090$ & 194.1800 & 194.1030 & -0.077 & 222 & 6.0 \\
\hline Chlorogenic acid & {$[\mathrm{M}+\mathrm{H}]+,[\mathrm{M}+\mathrm{K}]+$} & $355.3124 ; 393.3296$ & 354.3100 & 354.3044 & -0.0056 & 222 & 6.5 \\
\hline
\end{tabular}

\subsection{Antioxidant Activity}

\subsubsection{DPPH Antiradical Test}

Considering the four concentrations $(50,100,200$ and $500 \mu \mathrm{g} / \mathrm{g}$ of free fat matter), the activity of extracts increased when concentration increased. In addition, antiradical activity was specific of each extract and the different genotype expressed different antioxidant activities. Results of antiradical activity of bioactive extracts showed that fermented dry beans had higher DPPH scavenging power than the dark chocolate. This corroborates the observations made by Urbanska et Kowalska (2019). This was confirmed by DPPH in vitro test. This is easily explained by the reduction in polyphenol content during roasting prior to chocolate production. This can be clearly seen with the high content of oligomeric procyanidins in beans than chocolate which exhibit higher antioxidant capacity than monomeric polyphenols. Therefore, beans of cocoa have excellent antioxidant properties than their corresponding dark chocolate bars (Di Mattia et al., 2017). Indeed, in beans, the highest DPPH was obtained with samples whose concentration of polyphenols was highest. The same results were obtained by Caporaso et al. (2018) and Tomas-Barberan (2012). It was observed that antioxidant activity was not directly link to the polyphenol content in chocolate. According to Urbanska et Kowalska (2019), the antioxidant character of chocolate is an extremely complex phenomenon which depends on many factors. It is therefore not possible to determine and correlate the polyphenolic content and antioxidant activity unequivocally. The beans of the hybrid ()SNK10 $\times(\widehat{\jmath})$ IMC67 showed the highest percentage of DPPH antiradical activity $(85.17 \%)$ considering the concentration of $500 \mu \mathrm{g} / \mathrm{ml}$ of extract solution (Fig. 4).

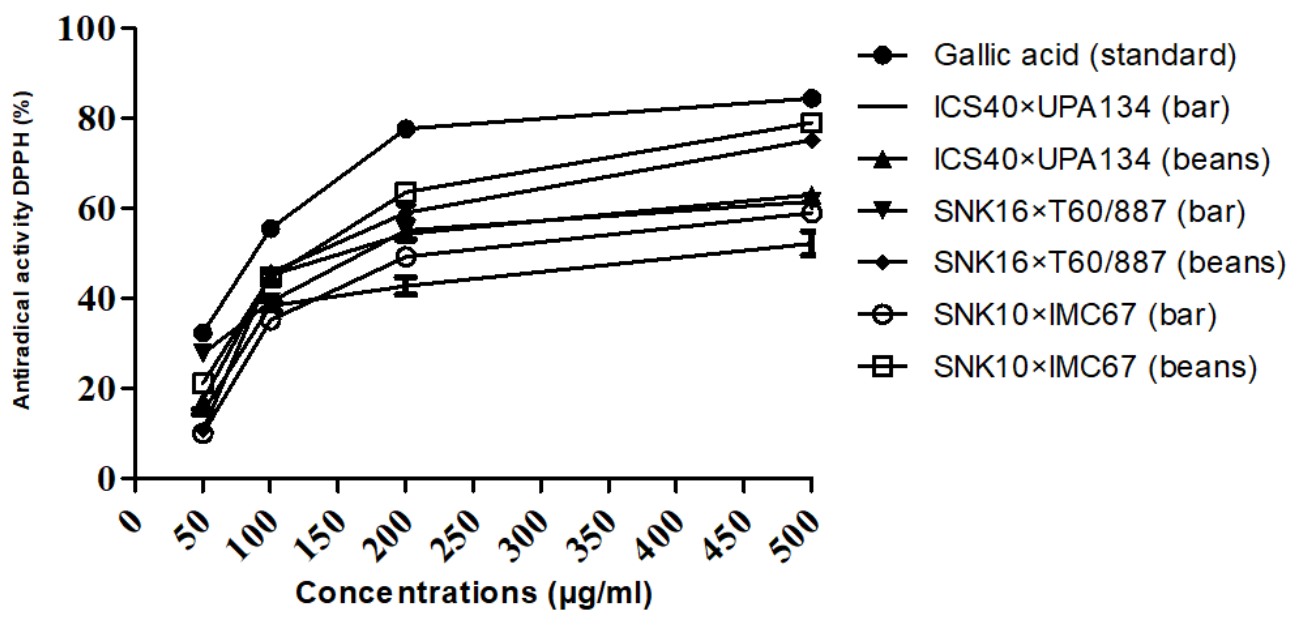

Figure 4. DPPH radical scavenging activity $(\%)$

The classification of antioxidant activity according to Scherer and Godoy (2009) showed four extracts with strong antioxidant activity and two others with moderate antioxidant activity (Table 3 ). Only one dark chocolate sample obtained from $($ ( $)$ ICS40×(đ)UPA134 hybrid displayed a strong antioxidant activity. 
Table 3. Scavenging activity $\left(\mathrm{EC}_{50}\right)$ and antioxidant activity index (AAI) of cocoa beans/chocolate on DPPH radicals

\begin{tabular}{|c|c|c|c|c|}
\hline Hybrids & Matrices & $\mathrm{EC}_{50} \mathrm{DPPH}(\mathrm{mg} / \mathrm{ml})$ & AAI & Antioxidant activity \\
\hline \multirow{3}{*}{ (q)SNK16×(ふ)T60/887 } & Gallic acid & $1.95 \pm 0.02^{\mathrm{a}}$ & $73.52 \pm 6.47^{\mathrm{d}}$ & Very strong \\
\hline & Beans & $125.4 \pm 12.31^{\mathrm{c}}$ & $1.14 \pm 0.04^{\mathrm{b}}$ & strong \\
\hline & Bar & $206.7 \pm 19.21^{\mathrm{e}}$ & $0.69 \pm 0.01^{\mathrm{a}}$ & moderate \\
\hline \multirow[t]{2}{*}{ (ㅇ)ICS40×(ð)UPA134 } & Beans & $107.2 \pm 9.54^{\mathrm{b}}$ & $1.33 \pm 0.03^{\mathrm{c}}$ & strong \\
\hline & Bar & $138.8 \pm 13.45^{\mathrm{cd}}$ & $1.03 \pm 0.02^{\mathrm{b}}$ & strong \\
\hline \multirow[t]{2}{*}{ (†)SNK10×(ठ゚)IMC67 } & Beans & $126.9 \pm 11.67^{\mathrm{c}}$ & $1.13 \pm 0.03^{\mathrm{b}}$ & strong \\
\hline & Bar & $145.6 \pm 14.03^{\mathrm{d}}$ & $0.98 \pm 0.02^{\mathrm{b}}$ & moderate \\
\hline
\end{tabular}

Values are expressed as means \pm standard deviation $(\mathrm{n}=3)$. Gallic acid was used as a standard. $\mathrm{EC}_{50}$ value is defined as the amount antioxidant necessary to decrease initial DPPH radical concentration by 50\%. AAI represents final concentration of DPPH in the reaction)/IC $\mathrm{C}_{50}$. Means with different letters in the same column were significantly different $(\mathrm{P}<0.05$, ANOVA)

At 5\% heterogeneity, the cluster below was obtained with antioxidant activity index (AAI) of cocoa beans/chocolate on DPPH radicals with three groups identified (Fig. 6). The first group comprised samples with strong antioxidant activity. This group is divided into two subgroups specifying by the matrix. The second group comprised beans from ( $(+)$ ICS40 $\times\left({ }^{\wedge}\right)$ UPA134 hybrid which displayed the strongest antioxidant activity . The third group comprised chocolate bar from $(+9) \mathrm{SNK} 16 \times\left({ }^{\lambda}\right) \mathrm{T} 60 / 887$ hybrid was classified as having the moderate antioxidant activity. The hierarchical classification demonstrated the fact that the antiradical activity is higher in cocoa beans than dark chocolate bars.

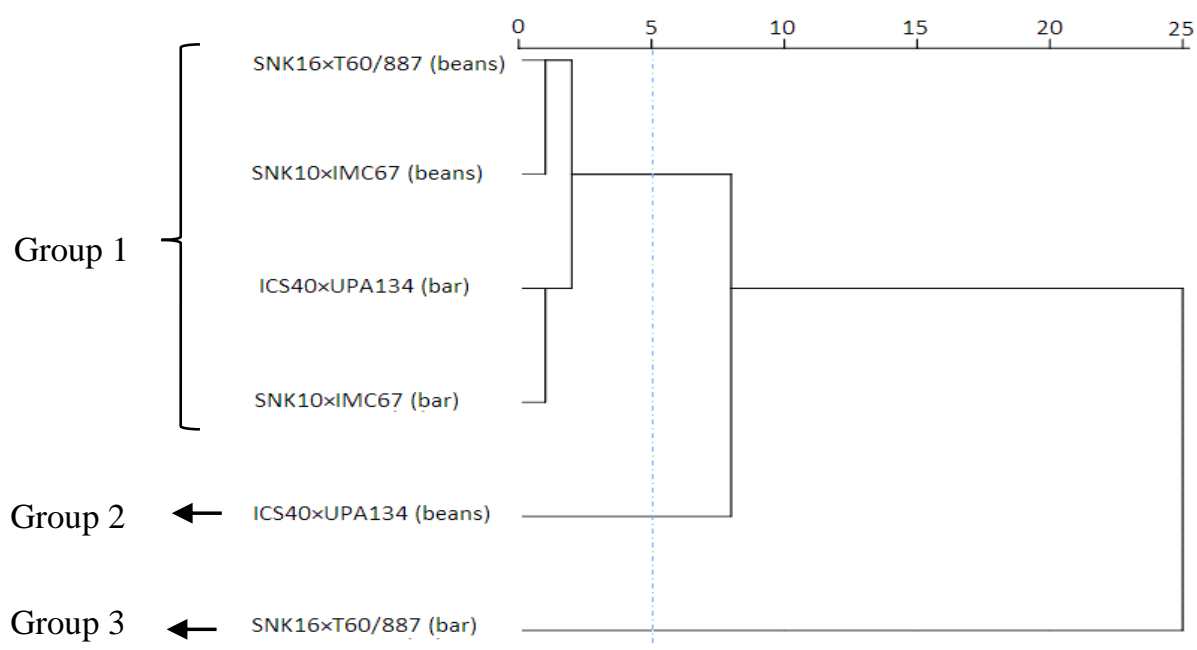

Figure 6. Hierarchical classification of cocoa beans/chocolate according to antioxidant activity index (AAI) on DPPH radicals

\subsubsection{Ferric Reducing/Antioxidant Activity Power}

The ferric reducing/antioxidant power (FRAP) showed different results in each matrix with the three considered hybrids. The reducing/antioxidant power of beans was higher than that of chocolate bars. The highest

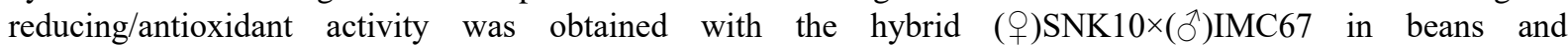
(P)SNK16 $\times\left({ }^{\top}\right) \mathrm{T} 60 / 887$ in bars $(93.05 \pm 1.91 \mu \mathrm{g} \mathrm{GAE} / \mathrm{mg}$ ffm and $75.47 \pm 2.08 \mu \mathrm{g}$ GAE/mg ffm respectively). There was a significant difference between dried fermented beans and dark chocolate bar ferric reducing capacity (Fig. 5). The hybrid ( + )ICS40 $\times\left({ }^{\Uparrow}\right)$ UPA134 showed a small difference with respect to the reducing power between beans and dark chocolate. The antioxidant capacity evaluated by the reactions of FRAP with extracts of beans and dark chocolate bars of each genotype varied according to the matrix and the genotype. According to the results displayed in Figures 5 and Table 1 as opposed to total polyphenol content (TPC), the antioxidant capacities of beans are higher compared to the antioxidant capacities of dark chocolate. This was confirmed by FRAP in vitro test. As earlier mentioned, the reduction in polyphenol content during roasting prior to chocolate production directly affected the antioxidant activity of chocolate. It is well-known that cocoa polyphenols are the major contributing factors to the overall antioxidant potential of cocoa and cocoa based 
products (Urbanska et al., 2020; Urbanska et Kowalska, 2019; Komes et al., 2013).

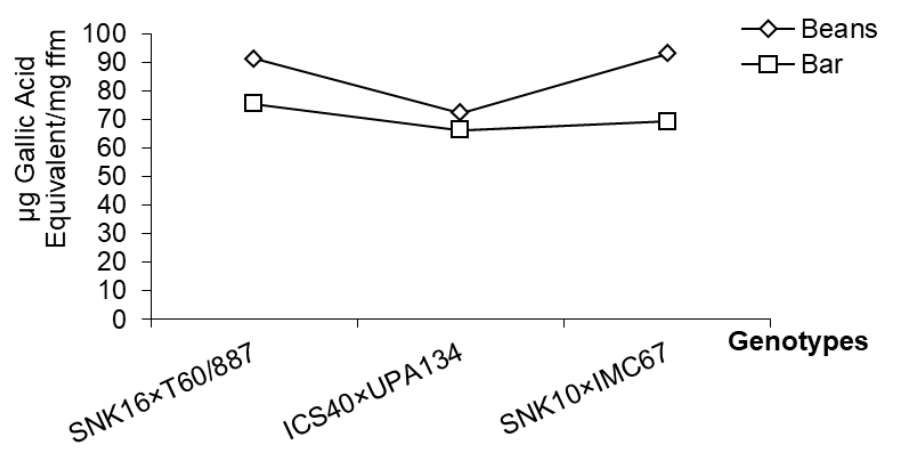

Figure 5. Ferric reducing/antioxidant power ( $\mu \mathrm{g} \mathrm{GAE/g} \mathrm{ffm)}$

\section{Conclusion}

The identification of methylxanthines and phenolic compounds in an extract is an interesting approach in predicting the antioxidant activities of the extract. The antioxidant activities of cocoa and cocoa based products especially dark chocolate is correlated to the content of bioactive compounds, mainly polyphenols. The content and the activity of each extract depend on the nature of the extract. This study shows that there is a progressive reduction in polyphenol content from fermented dry beans to dark chocolate resulting to a significant decrease in peak intensities of monomeric compounds. The UPLC-DAD-ESI-MS allows the identification of individual bioactive compounds in cocoa beans or cocoa based products. This method could be a rapid way of identifying major individual bioactive compounds in cocoa and cocoa based products. This study therefore shows a relative difference between cocoa hybrids with respect to polyphenol and proanthocyanidin contents, the composition in individual compounds and their antioxidant properties. The antioxidant activity of cocoa is determined by the polyphenol content in cocoa beans. In dark chocolate, the antioxidant activity was a function of polyphenol content which is directly related to the thermic processes employed. Future works will focus on the identification and quantification of individual bioactive compounds on a large scale sampling of genotypes using different liquid chromatographic methods.

\section{Conflict of Interest}

The author(s) declare no potential conflicts of interest with respect to the research, authorship, and/or publication of this article.

\section{Acknowledgments}

The authors express gratitude to the Institute of Agricultural Research for Development (IRAD) for chocolate production and the Laboratory of Organic Synthesis and Natural Products for identification of molecular structures.

AKOA Simon Perrez ORCID Number https://orcid.org/0000-0002-8934-3338

EFFA ONOMO Pierre ORCID Number https://orcid.org/0000-0002-5076-1882

\section{References}

Afoakwa, E. O., Paterson, A., \& Fowler, M. (2007). Factors influencing rheological and textural qualities in chocolate-a review. Trends in Food Science \& Technology, 18, 290-298. https://doi.org/10.1016/j.tifs.2007.02.002

Albertini, B., Schoubben, A., Guarnaccia, D., Pinelli, P., Vecchia, M. D., Ricci, M., Di Renzo, G. C., \& Blasi, P. (2015). Effect of Fermentation and Drying on Cocoa Polyphenols. Journal of Agricultural and Food chemistry, 63, 9948-9953. https://doi.org/10.1021/acs.jafc.5b01062

Aprotosoaie, A. C., Luca, S. V., \& Miron, A. (2016). Flavor chemistry of cocoa and cocoa products-An overview. Comprehensive Review in Food Science and Food Safety, 15, 73-91. https://doi.org/10.1111/1541-4337.12180

Aprotosoaie, A.C., \& Stanescu U. (2010). Alkaloids-biogene compounds with therapeutic use. Iasi: Gr.T.Popa Publishing House. 
Ashihara, H., \& Suzuki, T. (2004). Distribution and biosynthesis of caffeine in plants. Frontières in Bioscience, 9, 1864-1876. https://doi.org/10.2741/1367

Barišic, V., Flanjak, I., Križic, I., Jozinovic, A., Šubaric, D., Babic, J., Milicevic, B., \& Ackar, D. (2019). Impact of high-voltage electric discharge treatment on cocoa shell phenolic components and methylxanthines. Journal of Food Processing and Engineering, 2019, e13057. https://doi.org/10.1111/jfpe.13057

Belscak, A., Komes, D., Horzic, D., Ganic, K. K., \& Karlovic, D. (2009) Comparative study of commercially available cocoa products in terms of their bioactive composition. Food Research International, 42, 707-716. https://doi.org/10.1016/j.foodres.2009.02.018

Benzie, I. F., \& Strain, J. J. (1996). The ferric reducing ability of plasma (FRAP) as a measure of 'antioxidant power': the FRAP assay. Anals of Biochemistry, 239, 70-76. https://doi.org/10.1006/abio.1996.0292

Bortolini, C., Patrone, V., Puglisi, E., \& Morelli, L. (2016). Detailed analyses of the bacterial populations in processed cocoa beans of different geographic origin, subject to varied fermentation conditions. International Journal of Food Microbiology, 236, 98-106. https://doi.org/10.1016/j.ijfoodmicro.2016.07.004

Camillo, J. A., \& Benitez, J. (2000). Clinical significant pharmacokinetic interaction between dietary caffeine and medications. Clinical Pharmacokinetic, 39, 127-53. https://doi.org/10.2165/00003088-200039020-00004

Caporaso, N., Whitworth, M. B., Fowler, M. S., \& Fisk, I. D. (2018). Hyperspectral imaging for non-destructive prediction of fermentation index, polyphenol content and antioxidant activity in single cocoa beans. Food Chemistry, 258, 343-351. https://doi.org/10.1016/j.foodchem.2018.03.039

Carrillo, L. C., Londoño-Londoño, J., \& Gil, A. (2014). Comparison of polyphenol, methylxanthines and antioxidant activity in Theobroma cacao beans from different cocoa-growing areas in Colombia. Food Research International, 60, 273-280. https://doi.org/10.1016/j.foodres.2013.06.019

Caudle, G. A., Gu, Y., \& Bell, L. N. (2001). Improved analysis of theobromine and caffeine in chocolate food products formulated with cocoa powder. Food Research International, 34, 599-603. https://doi.org/10.1016/S0963-9969(01)00077-1

Cuatrecasas, J. (1964). Cacao and its allies: A taxonomic revision on the genus Theobroma. Bulletin of the United States National Museum. Washington: Smithsonian Institution, 35, 79-614.

Di Mattia, C. D., Sacchetti, G., Mastrocola, D., \& Serafini, M. (217). From cocoa to chocolate: The impact of processing on in vitro antioxidant activity and the e ects of chocolate on antioxidant markers in vivo. Frontiers in Immunology, 8, 1207. http://dx.doi.org/10/3389/fimmu.2017.01207

Efombagn, I. B. M., Motomayor, J. C., Sounigo, O., Eskes, A. B., Nyassé, S., Cilas, C., Schnell, R., Manzanares-Dauleux, M. J., \& Kolesnikovaallen, M. (2008). Genetic diversity and structure of farm and GenBank accessions of cacao (Theobroma cacao L.) in Cameroon revealed by microsatellite markers. Tree Genetics \& Genomes, 4, 821-831. https://doi.org/10.1007/s11295-008-0155-z

Evans, S. M., \& Griffiths, R. R. (1999). Caffeine withdrawal: a parametric analysis of caffeine dosing conditions. Journal Pharmacological Experiment Therapy, 289, 285-294.

Faisil, Amin, I., \& Norhaizan, M. E. (2013). Identification of phenolic compounds in polyphenols-rich extract of Malaysian cocoa powder using the HPLC-UV-ESI-MS/MS and probing their antioxidant properties. Food Science and Technolology, 67, 3150-3158.

Franco, R., Onatibia-Astibia, A., \& Martınez-Pinilla, E. (2013). Health benefits of methylxanthines in cacao and chocolate. Nutrients, 5, 4159-73. https://doi.org/10.3390/nu5104159

Giacometti, J., Jolic, S. M., \& Josic, D. (2015). Cocoa processing and impact on composition. In V. R. Preedy (Ed.), Processing and impact on active components in food (pp. 605-12). London/Waltham/San Diego: Academic Press. https://doi.org/10.1016/B978-0-12-404699-3.00073-1

Gómez-Juaristi, M., Sarriá, B., Martínez-López, S., Bravo-Clemente, L., \& Mateos, R. (2019). Flavanol bioavailability in two cocoa products with different phenolic content: a comparative study in humans. Nutrients, 11(7), 1441. https://doi.org/10.3390/nu11071441

González-Barrio, R., Nuñez-Gomez, V., Cienfuegos-Jovellanos, E., García-Alonso, F. R., \& Periago-Castón, M. J. (2020). Improvement of the Flavanol Profile and the Antioxidant Capacity of Chocolate Using a Phenolic Rich Cocoa Powder. Foods, 9, 189. https://doi.org/10.3390/foods9020189 
Guehi-François, G. (2019). Impact de la fermentation sur les propriétés antioxydantes, anti-inflammatoires et immunomodulatrices du cacao. Thèse pour obtenir le grade de docteur de l'Université de Montpellier, Université Montpellier, France.

Hagerman, A. E. (2002). Acid butanol assay for proanthocyanidins. Tannin Handbook, Philadelphia, USA. Retrieved from http://www.users.miamioh.edu/hagermae/

Hernández-Hernández, C., Viera-Alcaide, I., Morales, S. A. M., Fernández-Bolaños, J., \& Rodríguez-Gutiérrez, G. (2018). Bioactive compounds in Mexican genotypes of cocoa cotyledon and husk. Food Chemistry, 240, 831-839. https://doi.org/10.1016/j.foodchem.2017.08.018

ICCO. (2019). Querterly Bulletin of Cocoa Statistics.

Ioannone, F., Di Mattia, C. D., De Gregorio, M., Sergi, M., Serafini, M., \& Sacchetti, G. (2015). Flavanols, proanthocyanidins and antioxidant activity changes during cocoa (Theobroma cacao L.) roasting as affected by temperature and time of processing. Food Chemistry, 174, 256-62.

https://doi.org/10.1016/j.foodchem.2014.11.019

Jia, L., Liu, X., Bai, Y. Y., Li, S. H., Sun, K., ... He, C. (2010). Short-term effect of cocoa product consumption on lipid profile: a meta-analysis of randomized controlled trials. American Journal of Clinical Nutrition, 92, 218-25. https://doi.org/10.3945/ajcn.2009.28202

Keen, C. L., Holt, R. R., Oteiza, P. I., Fraga, C. G., \& Schmitz, H. H. (2005). Cocoa antioxidants and cardiovascular health. American Journal of Clinical Nutrition, 81(suppl), 298-303. https://doi.org/10.1093/ajcn/81.1.298S

Khan, N., \& Nicod, N. M. (2012). Biomarkers of cocoa consumption. In R. Paoletti, A. Poli, A. Conti, \& F. Visioli (Eds.), Chocolate and health (pp. 33-41). Milan/Dordrecht/Heidelberg/London/New York: Springer-Verlag. https://doi.org/10.1007/978-88-470-2038-2_3

Komes, D., Belščak-Cvitanovič, A., Škrabal, S., Vojvodič, A., \& Bušič, A. (2013). The influence of dried fruits enrichment on sensory properties of bitter and milk chocolates and bioactive content of their extracts affected by different solvents. LWT - Food Science and Technology, 53, 360-369.

Kongor, J. E., Hinneh, M., de Walle, D. V., Afoakwa, E. O., Boeckx, P., \& Dewettinck, K. (2016). Factors influencing quality variation in cocoa (Theobroma cacao) bean flavour profile. A review. Food Research International, 82, 44-52. https://doi.org/10.1016/j.foodres.2016.01.012

Kothe, L., Zimmermann, B. F., \& Galensa, R. (2013). Temperature influences epimerization and composition of flavanol monomers, dimers and trimers during cocoa bean roasting. Food Chemistry, 141, 3656-63. https://doi.org/10.1016/j.foodchem.2013.06.049

Lecumbersi, E., Mateos, R., Izzuirdo-Pulido, M., Ruperez, P., Goya, L., \& La Bravo, L. (2007). Dietary fibre composition, antioxidant capacity and physico-chemical properties of fibre rich product from cocoa (Theobroma cacao, L). Food Chemistry, 104, 948-954. https://doi.org/10.1016/j.foodchem.2006.12.054

Liu, J., Liu, M., He, C., Song, H., Guo, J., Wang, Y., Yang, H., \& Su, X. (2015). A comparative study of aroma-active compounds between dark and milk chocolate: relationship to sensory perception. Journal of Science of Food Agriculture, 95, 1362-1372. https://doi.org/10.1002/jsfa.6831

Loor Solórzano, G. R. (2007). Contribution à l'étude de la domestication de la variété de cacaoyer Nacional d'Équateur : recherche de la variété native et de ses ancêtres sauvages. Thèse pour l'obtention du grade de docteur en sciences agronomiques. Ecole Nationale Supérieure Agronomique de Montpellier, Montpellier supagro, France.

Martínez-López, S., Sarriá, B., Gómez-Juaristi, M., Goya, L., Mateos, R., \& Bravo-Clemente, L. (2014a). Theobromine, caffeine, and theophylline metabolites in human plasma and urine after consumption of soluble cocoa products with different methylxanthine contents. Food Research International, 63, 446-455. https://doi.org/10.1016/j.foodres.2014.03.009

Martínez-López, S., Sarriá, B., Sierra-Cinos, J. L., Goya, L., Mateos, R., \& Bravo, L. (2014b). Realistic intake of a flavanol-rich soluble cocoa product increases HDL-cholesterol without inducing anthropometric changes in healthy and moderately hypercholesterolemic subjects. Food \& Function, 5(2), 364-374. https://doi.org/10.1039/c3fo60352k

Mikołajczak, N., \& Tanska, M. (2020). Relationships between cocoa mass percentage,surfaccolor, free phenolic compounds content and antioxidant capacity of commercially available dark chocolate bars. Journal of 
Food Science and Technology. https://doi.org/10.1007/s13197-020-04898-1

Niemenak, N., Rohsius, C., Elwers, S., Omokolo Ndoumou, D., \& Lieberei, R. (2006). Comparative study of different cocoa (Theobroma cacao L.) clones in terms of their phenolics and anthocyanins contents. Journal of Food Composition and Analysis, 19, 612-619. https://doi.org/10.1016/j.jfca.2005.02.006

Noor-Ariefandie, F., \& Fan, Z. (2019). Intravariety Diversity of Bioactive Compounds in Trinitario Cocoa Beans with Different Degrees of Fermentation. Journal of Agricultural and Food Chemistry, 67, 3150-3158. https://doi.org/10.1021/acs.jafc.8b06418

Noor-Soffalina, S. S., Jinap, S., Nazamid, S., \& Nazimah, S. A. H. (2009). Effect of polyphenol and pH on cocoa Maillard-related flavour precursors in a lipidic model system. International Journal of Food Science and Technology, 44, 168-80. https://doi.org/10.1111/j.1365-2621.2008.01711.x

Oracz, J., Zyzelewicz, D., \& Ewa Nebesny, E. (2015). The Content of Polyphenolic Compounds in Cocoa Beans (Theobroma cacao L.), Depending on Variety, Growing Region, and Processing Operation. Critical Review in Food Science and Nutrition, 55, 1176-1192. https://doi.org/10.1080/10408398.2012.686934

Patras, M. A., Milev, M. P., Vrancken, G., \& Kuhnert, N. (2014). Identification of novel cocoa flavonoids fromraw fermented cocoa beans by HPLC-MSn. Food Research International, 63, 353-359. https://doi.org/10.1016/j.foodres.2014.05.031

Peláez, P. P., Bardón, I., \& Camasca, P. (2016). Methylxanthine and catechin content of fresh and fermented cocoa beans, dried cocoa beans, and cocoa liquor. Scientia Agropecuaria, 7, 355-365. https://doi.org/10.17268/sci.agropecu.2016.04.01

Ramli, N., Hassan, O., Said, M., Samsudin, W., \& Idris, N. A. (2006). Influence of roasting conditions on volatile flavor of roasted Malaysian cocoa beans. Journal of Food Processing and Preservation, 30, 280-98. https://doi.org/10.1111/j.1745-4549.2006.00065.x

Rimbach, G., Melchin, M., Moehring, J., \& Wagner, A. E. (2009). Polyphenols from Cocoa and Vascular Health. A Critical Review. International Journal of Molecular Science, 10, 4290-4309. https://doi.org/10.3390/ijms10104290

Rao, N. Z., \& Fuller, M. (2018). Acidity and antioxidant activity of cold brew coffee. Scientific Reports, 8. https://doi.org/10.1038/s41598-018-34392-w

Sarriá, B., Gomez-Juaristi, M., Martínez López, S., García Cordero, J., Bravo L., \& Mateos Briz, M. R. (2020). Cocoa colonic phenolic metabolites are related to HDL-cholesterol raising effects and methylxanthine metabolites and insoluble dietary fibre to anti-inflammatory and hypoglycemic effects in humans. PeerJ. https://doi.org/10.7717/peerj.9953

Scherer, R., \& Godoy, H. T. (2009). Antioxidant activity index (AAI) by the 2,2-diphenyl-1-picrylhydrazyl method. Food Chemistry, 112(3), 654-658. http://dx.doi.org/10.1016/j.foodchem.2008.06.026

Simirgiotis, M. J., Benites, J., Areche, C., \& Sepúlveda, B. (2015). Antioxidant Capacities and Analysis of Phenolic Compounds in Three Endemic Nolana Species by HPLC-PDA-ESI-MS. Molecules, 20, 11490-11507. https://doi.org/10.3390/molecules200611490

Singleton, V. L., \& Rossi, J. A. (1965). Colorimetry of total phenolics with phosphomolibdic Phosphotungstic acid reagent. American Journal of Enology and Viticulture, 37, 144-158.

Sorond, F. (2008). Cerebral Blood Flow Response to Flavanol-Rich Cocoa in Healthy Elderly Humans. Neuropsychiatric Diseases Treatment, 4, 433-440. https://doi.org/10.2147/NDT.S2310

Tomas-Barberan, F. A. (2012). Types, food sources, consumption and bioavailability of dietary polyphenols nutrinsight. In Proceedings of the Symposium $11^{\text {th }}$ Nutrition Conference, Kraft Foods.

Torres-Moreno, M., Tarrega, A., Costell, E., \& Blanch, C. (2012). Dark chocolate acceptability: influence of cocoa origin and processing conditions. Journal of Science Food Agriculture, 92, 404-11. https://doi.org/10.1002/jsfa.4592

Urbańska, B., Derewiaka, D., Lenart, A., \& Kowalska, J. (2019). Changes in the composition and content of polyphenols in chocolate resulting from pre-treatment method of cocoa beans and technological process. European Food Research and Technology, 245, 2101-2112. https://doi.org/10.1007/s00217-019-03333-w

Urbanska, B., \& Kowalska, J. (2019). Comparison of the Total Polyphenol Content and Antioxidant Activity of Chocolate Obtained from Roasted and Unroasted Cocoa Beans from Different Regions of the World. 
Antioxidants, 8, 283. https://doi.org/10.3390/antiox8080283

Urbanska, B., Szafranski, T., Kowalska, H., \& Kowalska, J. (2020). Study of Polyphenol Content and Antioxidant Properties of Various Mix of Chocolate Milk Masses with Different Protein Content. Antioxidants, 9, 299. https://doi.org/10.3390/antiox9040299

Wollgast, J., \& Anklam, E. (2000). Review on polyphenols in theobroma cacao: changes in composition during the manufacture of chocolate and methodology for identification and quantification. Food Research International, 33, 423-447. https://doi.org/10.1016/S0963-9969(00)00068-5

\section{Copyrights}

Copyright for this article is retained by the author(s), with first publication rights granted to the journal.

This is an open-access article distributed under the terms and conditions of the Creative Commons Attribution license (http://creativecommons.org/licenses/by/4.0/). 